\title{
Lucratividade da Gestão Integrada de Resíduos em uma Indústria de Refrigerante
}

A Gestão Integrada de Resíduos é uma metodologia que inclui todas as ações voltadas para o gerenciamento de resíduos sólidos, desde sua geração até o destino final, uma maneira que as empresas estão utilizando que se tornou de grande importância dentro de uma organização. É ainda a integração dos processos em busca da otimização da eficiência das empresas melhorando seu desempenho. Na busca em satisfazer às exigências dos clientes e para ajudar a impulsionar a vantagem competitiva e melhorar a eficiência do negócio, uma empresa especializada em gestão ambiental na cidade de Maracanaú - Ceará, buscou a estruturação do seu processo através da caracterização e análise de mercado. A Gestão Integrada de Resíduos implantado possibilitou resultados positivos e de forma eficiente atendem as normas e leis ambientais, bem como a satisfação do cliente, aumento dos lucros, evitando retrabalhos, custos desnecessários e não conformidades. 0 presente trabalho apresenta um dos serviços e os resultados que a empresa em questão, desempenha através da prestação dos serviços de coleta, separação, compra, transporte, reciclagem e destinação final de resíduos sólidos. O grande diferencial da empresa, é levar ao cliente a tranquilidade em saber que o serviço de gerenciar seu resíduo de forma correta na fábrica e com uma equipe preparada pode trazer resultados lucrativos, outro grande diferencial é que o cliente ganha com esse serviço, ao invés de ser um custo adicional e uma grande despesa, a indústria lucra, pois, a empresa especializada compra o resíduo gerado pela fábrica ao mesmo tempo que o gerencia. Os resultados apresentados no trabalho, destacam que a Gestão Integrada de Resíduos atuando de uma forma planejada e estratégica, gera lucros, economia de tempo e custos, otimização em serviços logísticos e operacionais, eficiência e eficácia com recursos internos, infraestrutura, satisfação do cliente e sustentabilidade.

Palavras-chave: Gestão Integrada de Resíduos; Lucro; Satisfação de Cliente.

\section{Profitability of Integrated Waste Management in a Soda Industry}

Integrated Waste Management is a methodology that includes all actions aimed at managing solid waste, from its generation to the final destination, a way that companies are using that has become of great importance within an organization. It is also the integration of the processes in search of the optimization of the efficiency of the companies improving their performance. In a quest to satisfy customer requirements and to help boost competitive advantage and improve business efficiency, a company specialized in environmental management in the city of Maracanaú - Ceará, sought to structure its process through the characterization and analysis of the market. Integrated Waste Management implemented positive results and efficiently meet environmental standards and laws, as well as customer satisfaction, increased profits, avoiding rework, unnecessary costs and nonconformities. The present work presents one of the services and the results that the company in question performs through the provision of the services of collection, separation, purchase, transportation, recycling and final destination of solid waste. The great difference of the company, is to take to the client the tranquility in knowing that the service of managing its waste in a correct way in the factory and with a prepared team can bring profitable results, another great differential is that the customer wins with this service, instead of being an additional cost and a great expense, the industry profits, therefore, the specialized company buys the waste generated by the factory at the same time that it manages it. The results presented in the paper emphasize that Integrated Waste Management, acting in a planned and strategic way, generates profits, saves time and costs, optimizes logistic and operational services, efficiency and effectiveness with internal resources, infrastructure, customer satisfaction and sustainability.

Keywords: Integrated Waste Management; Profit; Customer Satisfaction.

Topic: Engenharia da Sustentabilidade

Reviewed anonymously in the process of blind peer.
Received: $15 / 10 / 2019$

Approved: 21/12/2019
João Luis Josino Soares

Faculdade Terra Nordeste, Brasil

http://lattes.cnpq.br/4714394538597175

joaojosino@hotmail.com

Francisco Valdecilio Ferreira da Silva (iD

Faculdade Terra Nordeste, Brasil

http://lattes.cnpq.br/9263173921223602

http://orcid.org/0000-0002-8243-4843

valdeciliosilva@hotmail.com

Edenise Mônica Puerari

Faculdade Terra Nordeste, Brasil

http://lattes.cnpq.br/9324013726285736

edepuerari@yahoo.com.br

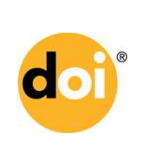

DOI: 10.6008/CBPC2179-684X.2019.004.0006
Karla Lúcia Batista Araújo

Centro Universitário Fametro, Brasil

http://lattes.cnpq.br/4520861312594048

karla.batista@hotmail.com

\section{Referencing this:}

SOARES, J. L. J.; SILVA, F. V. F.; PUERARI, E. M.; ARAÚJO, K. L. B.. Lucratividade da Gestão Integrada de Resíduos em uma Indústria de Refrigerante. Revista Brasileira de Administração Científica, v.10, n.4, p.87-98, 2019. DOI: http://doi.org/10.6008/CBPC2179684X.2019.004.0006 


\section{INTRODUÇÃO}

A sustentabilidade se tornou um princípio, onde o uso dos recursos naturais para a satisfação de necessidades presentes não pode comprometer a satisfação das necessidades das gerações futuras. Com isso, a temática relacionada aos Resíduos Sólidos, vem frequentemente sendo discutida em decorrência de seus impactos negativos ao meio ambiente. Com o desenvolvimento urbano e o crescimento econômico, novos padrões de produção e consumo se estabelecem, destacando as novas tecnologias alternativas para descarte de resíduos.

A Lei Federal 12.305 de 2010, que institui a Política Nacional de Resíduos Sólidos, vem estabelecer os princípios, objetivos e instrumentos, bem como as diretrizes relativas à gestão integrada e ao gerenciamento de resíduos sólidos, as responsabilidades dos geradores e do poder público e os instrumentos econômicos aplicáveis. A lei visa desenvolver, além da mudança comportamental da sociedade, o engajamento do poder público (IBGE, 2010).

Diante das preocupações atuais apresentadas e das exigências legais, as empresas vêm mudando seu comportamento de gerenciar os resíduos. No caso da indústria de bebidas, todo material derivado de sobra da produção, que não possui mais utilidade após determinado processo, são geralmente descartados e tratados como indesejáveis, no entanto, sua geração acaba sendo inevitável. Muitas vezes por falta de conhecimento ou por negligência, algumas empresas descartam esses resíduos sem o tratamento adequado, com isso, essas empresas deixam de faturar e aumentar sua receita por não fazer a comercialização dos materiais recicláveis.

A adesão de programas de gestão ambiental, treinamentos técnicos e palestras de educação ambiental são alicerces para um bom gerenciamento dos resíduos e uma coleta seletiva bem sucedida. Sabese que não se pode gerenciar o que não se conhece, portanto, para a implantação de qualquer programa de gestão de resíduos, ou mesmo, para implantação de uma coleta seletiva principalmente em um estabelecimento de grande porte como é o caso dessa indústria de bebidas, se faz necessário conhecer a composição e a quantidade dos resíduos gerados.

No presente trabalho são apresentados os dados levantados com o quantitativo e a lucratividade que o resíduo gera tanto para a indústria como para o prestador de serviço, consistindo em identificar o volume de cada resíduo, papel, metal, vidro e plástico bem como suas subclasses, o resíduo é comercializado separadamente com valor diferenciado, isso facilita na prestação dos serviços na coleta para o destino final. Ainda, será apresentado como a implantação da gestão de resíduos pode reverter despesas em receita.

Vale ressaltar que para prestar serviços de gestão de resíduos em grandes indústrias se faz necessário licenças de Órgãos Federais, Estaduais e Municipais e ainda apresentar condicionantes conforme periodicidade exigida pelo órgão. O objetivo principal deste artigo é apresentar a vantagem da implantação da gestão integrada de resíduos dentro de uma empresa, apresentado a receita e as estratégias que a empresa utiliza para obter resultados favoráveis e como objetivos específicos a) levantar dados reais com a implantação da gestão integrada de resíduos dentro de uma indústria de bebidas apresentado a lucratividade 
e os resultados em um período de três meses; b) levantar a quantidade e valores dos resíduos reciclados e não reciclados; c) Expressar a lucratividade dos resíduos destinados para reciclagem.

\section{REVISÃO TEÓRICA}

A gestão de resíduos para indústria de bebidas representa um conjunto de ações ambientalmente adequadas nas etapas de coleta, armazenamento, transporte, tratamento, destino final e disposição final, com o objetivo de minimizar os efeitos adversos que o resíduo pode causar a saúde e ao meio ambiente. Os resíduos sólidos gerados na indústria de bebidas constituem um grave problema ambiental, devido sua diversidade e quantidade em que são gerados. Portanto é dever do gerador gerenciá-los adequadamente. Essa parte do trabalho foi dividida em tópicos, conforme mostrado a seguir.

\section{Gestão integrada de resíduos reciclados}

No Brasil, a gestão dos resíduos até meados de 2010 era de responsabilidade total da administração pública. Então era ela quem ditava as regras e arcava com os custos da reciclagem, coleta e destinação dos resíduos. Assim a participação da iniciativa privada só era possível através de licitações, o que dificultava a implantação de ideias inovadoras (FERREIRA, 2018).

A Lei Federal brasileira no 12.305/2010 mudou esse cenário onde grandes mudanças aconteceram. Com o propósito de instituir a responsabilidade compartilhada a Política Nacional de Resíduos Sólidos (PNRS) descentralizou o poder da iniciativa pública. Assim, a responsabilidade pelo ciclo de vida dos resíduos foi dividida entre o poder público, iniciativa privada e os consumidores. Além disso, outro aliado importante foi a definição clara e por ordem de importância dos principais objetivos da PNRS. Sendo a não geração, redução, reutilização, reciclagem e tratamento dos resíduos sólidos, bem como disposição final ambientalmente adequada dos rejeitos.

Esse conjunto de ações possibilitou a implantação de um sistema gestão de integrada de resíduos sólidos. Bem como a atuação da iniciativa privada ouvindo e atendendo as necessidades dos consumidores sob a fiscalização do poder público. Portanto, os problemas ambientais advindos dos resíduos sólidos passaram a ser solucionados via consultoria e prestação de serviços de terceiros (FERREIRA, 2018).

\section{Contextualização de coleta seletiva x lucro}

O conceito de coleta seletiva apresenta- se como a forma de recolhimento diferenciado de materiais recicláveis, previamente separados nas fontes geradoras, por catadores, entidades, prefeituras e a sociedade em geral. Mesmo assim, vale esclarecer que não adianta separar os materiais recicláveis se não houver um sistema de recolhimento adequado para os materiais selecionados, pois a coleta seletiva viabiliza que os materiais separados sejam recuperados para a reciclagem, reuso ou compostagem. Além disso, torna-se necessário que a coleta seletiva seja baseada na forma de separação, reciclagem, informação motivacional e o mercado que vai absorver o material recuperado (CARVALHO, 2008). Na busca de uma tendência mundial 
voltada à padronização da reciclagem, o Conselho Nacional do Meio Ambiente - CONAMA, criou um padrão e código para os diferentes tipos de resíduos (Figura 1).

\begin{tabular}{|c|c|}
\hline Cores & Resíduos \\
\hline AZUL & papel/papelão \\
\hline VERMELHO & plástico \\
\hline VERDE & vidro \\
\hline AMARELO & Metal \\
\hline PRETO & Madeira \\
\hline LARANJA & resíduos perigosos \\
\hline BRANCO & resíduos ambulatoriais e de serviços de saúde \\
\hline ROXO & resíduos radioativos \\
\hline MARROM & resíduos orgânicos \\
\hline CINZA & $\begin{array}{c}\text { resíduo geral não reciclável ou misturado e } \\
\text { contaminado não passivel de separação. }\end{array}$ \\
\hline
\end{tabular}

Figura 1: Cores da Coleta Seletiva.

Segundo Vilhena (1999), a Coleta Seletiva é o processo de recolhimento e separação de materiais recicláveis (papel, vidro, metal, plástico e orgânico) que serão enviados para reciclagem. Denomina-se reciclagem o processo de beneficiamento de materiais recicláveis tais como papel, vidro, plástico e metal com a finalidade de transformá-los em novos produtos para comercialização (MONTEIRO et al., 2001).

Diante do conceito de coleta seletiva, as empresas vêm trabalhando para ter lucratividade com o próprio resíduo gerado. Como é o caso da empresa referência neste estudo, onde após a implantação da gestão integrada de resíduos, obteve lucros ao invés de despesas com destinação de resíduos. O resíduo que antes era destinado para aterro sanitário gerando despesas para empresa, com a implantação da gestão de resíduos, essa despesa passa a ser receita, além de reduzir o impacto com a geração de resíduos ao meio ambiente.

\section{Reciclagem}

Reciclagem é o processo de reaproveitamento de matéria prima, reaproveitando-o para outros fins. Este processo pode ser artesanal ou industrial. A reciclagem gera economia de matéria-prima, energia e diminuí a quantidade de lixo jogado na natureza e em aterros sanitários (CARVALHO, 2005). O retorno da matéria ao ciclo de produção, também pode ser denominado reciclagem. É o que convencionado pelas indústrias por logística reversa, que trata de retorno de produtos, embalagens ou materiais ao seu centro produtivo, trazendo retorno às empresas (HEIDEN, 2007).

O processo de reciclagem além de preservar o meio ambiente gera lucros, pois os materiais reciclados podem ser vendidos ou transformados em outros para ser vendido, gera empregos, pois é necessárias pessoas para a coleta e separação dos materiais e traz crescimento sustentável (LACERDA, 2006). A reciclagem é a solução mais viável e ambientalmente correta para a destinação do lixo, pois, com o crescimento populacional e o crescente consumo da população, a produção de lixo é muito grande e a armazenagem está ficando cada vez mais complicada e difícil, pois não há locais adequados para construção e implantação de aterros sanitários e a vida útil deste também está reduzida (LACERDA, 2006). 


\section{METODOLOGIA}

A pesquisa é um estudo de caso descritivo onde a coleta de dados foi realizada em uma terceirizada de gestão integrada de resíduos, que atua em uma empresa de fabricação de refrigerantes. O processo se deu por intermédio de análise de documentos, visita in loco, softwares e reuniões. O estudo de caso apresenta a vantagem da implantação da gestão integrada de resíduos dentro de uma empresa, apresentado a receita e as estratégias que a empresa utiliza para obter resultados favoráveis identificando aspectos organizacionais e econômicos da atividade de gestão de resíduos levantando dados quantitativos e com uso de dados secundários disponibilizados pela empresa terceirizada. Optou-se por este local devido sua importância e facilidade de acesso na obtenção de informações. Segundo Yin (2001), o estudo de caso tenta esclarecer uma decisão ou um conjunto de decisões: o motivo pelo qual foram tomadas, como foram implementadas e com quais resultados foram feitos a pesquisa.

A empresa estudada possui sua sede localizada em Maracanaú-Ceará, e atua em grandes indústrias dos ramos de bebidas, calçados, veículos, centros comerciais, indústria têxtil, hospitais, siderúrgica, dentre outros, com atuação em serviços de limpeza, portaria, manutenção predial e gestão de resíduos. Como diferencial em seus serviços, a empresa utiliza a gestão total de resíduos dentro do espaço industrial, utilizando a figura de operadores ambientais, que são funcionários especializados em fazer a triagem e acondicionamento correto dos resíduos, além de oferecer estratégias operacionais para melhor atender o cliente e as demandas de resíduos que são descartados na fabricação.

O levantamento apresentado teve um período de 3 meses, sendo de Janeiro a Março de 2019, os valores são dados reais disponibilizados pela empresa de gerenciamento do resíduo. O Aterro Sanitário destacado neste trabalho é o ASMOC - Aterro Sanitário Municipal Oeste de Caucaia, que atende a região metropolitana e a capital, Fortaleza-Ceará.

Dentre os vários contratos que a empresa atua, um deles é na fábrica de bebidas situada também no município de Maracanaú-Ceará. A empresa onde é prestado o serviço atua como responsável pela fabricação, comercialização e distribuição de bebidas nas regiões Norte, Nordeste e Centro-Oeste, com uma das maiores estruturas da marca no mundo, a fábrica funciona 24 horas por dia de domingo a domingo, sua geração de resíduos gira em torno de 200 a 250 toneladas por mês, que se destinado de forma inadequada seria um grande problema ambiental para região.

Para atingir os objetivos estabelecidos a pesquisa foi realizada pelo funcionário da empresa, em que obteve os dados através de sistema, prática e experiência com a gestão integrada de resíduos, realizando a verificação e análise no sistema onde cada carga de resíduo retirado da fábrica era dada baixa no sistema utilizado pela empresa. Para chegar aos resultados apresentados, desde a geração do resíduo até o destino final segue um fluxo ilustrado na Figura 2, que diariamente, em sua rotina, a fábrica envia para a central de resíduos os materiais que são descartados por falhas na produção, erro de lote, falha no produto, máquinas ou erro manual. Abaixo o fluxograma detalhado referente ao processo de entrada e saída e material na central de resíduos. 


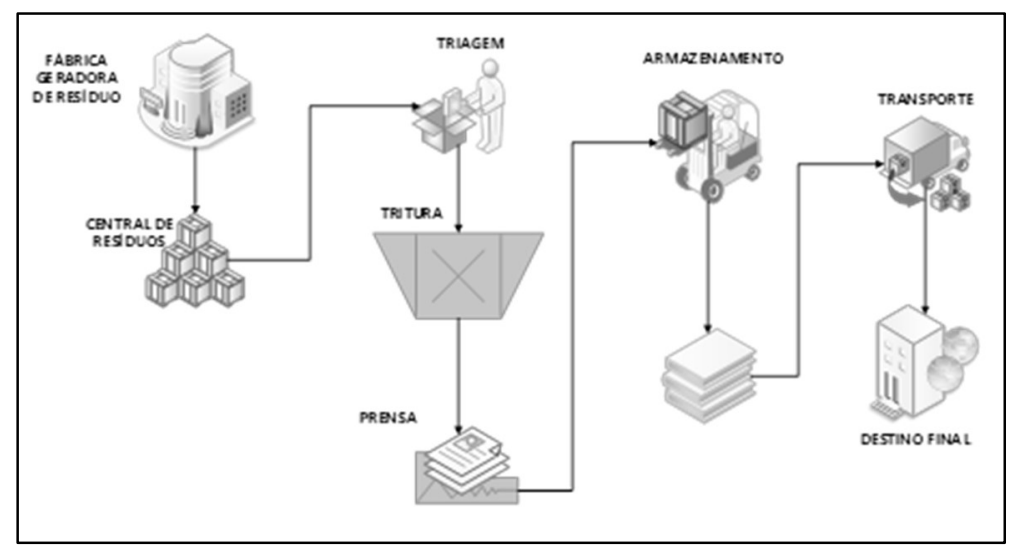

Figura 2: Entrada e Saída de Material na Central de Resíduos.

O material chegando na central é feito a triagem, ou seja, a separação e alocado em baias, na mesma central possui máquinas de tritura e prensa, onde alguns materiais é disposto, como exemplo, a lata de alumínio que são prensadas formando fardos, essa estratégia tem como vantagem o espaço para alocar nos caminhões de coleta, o peso aumenta e ainda é possível enviar um maior volume de material para destino final.

A Central de Resíduos possui uma área aproximada de $460 \mathrm{~m}^{2}$, composta por baia para resíduo de papelão $50 \mathrm{~m}^{2}$, baia para resíduo de Pet e Filme $50 \mathrm{~m}^{2}$, baia para bombonas $20 \mathrm{~m}^{2}$, baia para resíduo de tampas plásticas e preforma $30 \mathrm{~m}^{2}$, baia para resíduo de ferro $30 \mathrm{~m}^{2}$, área de máquinas $80 \mathrm{~m}^{2}$, área de carregamento $60 \mathrm{~m}^{2}$, escritório $15 \mathrm{~m}^{2}$, área para quebra de vidro $200 \mathrm{~m}^{2}$, com equipamentos de prensa e tritura, a área é equipada e dentro dos padrões de segurança do trabalho, com sinalização, linha de vida, identificação, piso industrial e impermeável, sala de apoio para os operadores ambientais e assistente de gestão ambiental.

\section{RESULTADOS E DISCUSSÃO}

A pesquisa tem por finalidade descrever e apresentar os dados quantitativos gerados pelo gerenciamento de residuos sólidos, através de dados levantados no período de Janeiro a Março de 2019. Por entender a grande importância dos materiais recicláveis no âmbito da gestão dos resíduos sólidos, o legislador infraconstitucional inseriu no texto da lei 12.305/10 vários dispositivos destinados à melhoria das condições de trabalho e aumento da renda dos profissionais da área.

Neste sentido, a PNRS - Política Nacional dos Resíduos Sólidos, tem como um dos seus princípios o reconhecimento do resíduo sólido reutilizável e reciclável como um bem econômico e valor social, gerador de trabalho e renda, e promotor da cidadania (BRASIL, 2010). A lei alerta para a necessidade de a sociedade entender que os resíduos gerados são produtos com valor venal e geradores de emprego e renda.

O Quadro 1, mostra a especificação do material, o volume e a despesa que a empresa gera sem a implantação do sistema de gerenciamento de resíduos, o levantamento apresentado teve um período de 3 meses. Os valores são dados reais disponibilizados pela empresa de gerenciamento. $\mathrm{O}$ aterro sanitário destacado neste trabalho é o ASMOC - Aterro Sanitário Municipal Oeste de Caucaia, que atende a região metropolitana e a capital, Fortaleza-Ceará. 
Pode ser observado, com os dados coletados, que um mau gerenciamento poderia proporcionar grande despesa para empresa, além da superlotação do aterro sanitário destinado. No Quadro 1, está destacado todos os materiais que são gerados pela empresa de refrigerantes, desde resíduos reciclados ao que não podem ser aproveitados para retornar a indústria. O levantamento está em medidas detalhadas em quilograma e toneladas, já que o aterro sanitário cobra pelo valor da tonelada.

Quadro 1: Destinação final Sem a Gestão Integrada de Resíduos.

\begin{tabular}{|l|l|l|l|l|}
\hline \multicolumn{5}{|c|}{ DESTINAÇ̃̃O FINAL SEM A GESTÃO INTEGRADA DE RESIDUOS } \\
\hline Mlumínio & $\begin{array}{c}\text { VOLUME } \\
\mathbf{3} \text { MESES (kg) }\end{array}$ & $\begin{array}{c}\text { VOLUME } \\
\text { 3 MESES (t) }\end{array}$ & \multicolumn{1}{c|}{ VALOR ATERRO SANITÁRIO (t) } & DESPESAS TRIMESTRAL (R\$) \\
\hline Ferro & 6.380 & 6,38 & 61,32 & 391,22 \\
\hline Preforma & 19.230 & 19,23 & 61,32 & $1.179,18$ \\
\hline Tampa Plástica & 11.490 & 11,49 & 61,32 & 704,57 \\
\hline Bombonas & 21.090 & 21,09 & 61,32 & $1.293,24$ \\
\hline Papelão & 2.280 & 2,28 & 61,32 & 139,81 \\
\hline Sucata de Geladeira & 52.530 & 52,53 & 61,32 & $3.221,14$ \\
\hline Pet Misto & 24 & 0,024 & 61,32 & 1,47 \\
\hline Filme Branco & 31.510 & 31,51 & 61,32 & $1.932,19$ \\
\hline Filme Misto & 19.970 & 19,97 & 61,32 & $1.224,56$ \\
\hline Vidro Misto & 1.070 & 1,07 & 61,32 & 65,61 \\
\hline Tetra Pak & 172.370 & 172,37 & 61,32 & $10.569,73$ \\
\hline Ref Pet & 1.860 & 1,86 & 61,32 & 114,06 \\
\hline Resíduo Organico & 77.810 & 77,81 & 61,32 & $4.771,31$ \\
\hline Resíduo Comum & 14.120 & 14,12 & 61,32 & 865,84 \\
\hline Lodo Ete & 67.280 & 67,28 & 61,32 & $4.125,61$ \\
\hline Carvão Ativado & 98.090 & 98,09 & 61,32 & $6.014,88$ \\
\hline TOTAL TRIMESTRE & 6.700 & 6,70 & 61,32 & 410,84 \\
\hline MÉDIA MENSAL & - & $\mathbf{6 0 3 , 8 0 4}$ & - & $\mathbf{R} \$ \mathbf{3 7 . 0 2 5 , 2 6}$ \\
\hline & - & $\mathbf{2 0 1 , 2 6 8}$ & - & $\mathbf{1 2 . 3 5 4 , 7 5}$ \\
\hline
\end{tabular}

Analisando o Quadro 1, tem-se que o valor da tonelada cobrada pelo aterro sanitário de CaucaiaCeará, é de $\mathrm{R} \$$ 61,32. Essa empresa gera mais 200 toneladas por mês. Em 1 ano se pode dizer que seriam destinados para aterro sanitário 2.400 toneladas de resíduos. Observando ainda que, a maioria dos resíduos são recicláveis, ou seja, podem ser (re)aproveitados na indústria para voltar ao mercado, podendo melhorar a economia de várias empresas. Pode-se considerar que neste modelo a empresa teria apenas despesa.

Fazendo um comparativo com o Quadro 2 que será apresentado em seguida, faz-se o levantamento desse mesmo material sendo destinado para reciclagem, onde o mesmo é processado e retorna para indústria. Os valores apresentados para venda de reciclado, são reais e pagos por empresas que recebem o resíduo de forma adequada e dentro das exigências legais e ambientais.

Quadro 2: Destinação Com a Gestão Integrada de Resíduos.

\begin{tabular}{|l|l|l|l|l|}
\hline \multicolumn{1}{|c|}{ MESTINAÇÃO COM A GESTÃO INTEGRADA DE RESIDUOS } \\
\hline VOLUME 3 MESES (kg) & $\begin{array}{c}\text { VOLUME } \\
\text { 3 MESES } \\
\mathbf{( t )}\end{array}$ & \multicolumn{1}{|c|}{$\begin{array}{c}\text { VALOR RECICLAGEM- KG } \\
\text { (R\$) }\end{array}$} & $\begin{array}{c}\text { RECEITA TRIMESTRAL } \\
\text { (R\$) }\end{array}$ \\
\hline Alumínio & 6.380 & 6,38 & 4,10 & $26.158,00$ \\
\hline Ferro & 19.230 & 19,23 & 0,32 & $6.153,60$ \\
\hline Preforma & 11.490 & 11,49 & 2,00 & $22.980,00$ \\
\hline Tampa Plástica & 21.090 & 21,09 & 1,60 & $33.744,00$ \\
\hline Bombonas & 2.280 & 2,28 & 1,20 & $2.736,00$ \\
\hline Papelão & 52.530 & 52,53 & 0,30 & $15.759,00$ \\
\hline Sucata de Geladeira & 24 & 0,024 & 20,00 & 480,00 \\
\hline Pet Misto & 31.510 & 31,51 & 1,00 & $31.510,00$ \\
\hline Filme Branco & 19.970 & 19,97 & 1,50 & $29.955,00$ \\
\hline
\end{tabular}




\begin{tabular}{|c|c|c|c|c|}
\hline Filme Misto & 1.070 & 1,07 & 1,00 & $1.070,00$ \\
\hline Vidro Misto & 172.370 & 172,37 & 0,07 & $12.065,90$ \\
\hline Tetra Pak & 1.860 & 1,86 & 0,14 & 260,40 \\
\hline Ref Pet & 77.810 & 77,81 & 0,60 & $46.686,00$ \\
\hline TOTAL TRIMESTRE & & 417,614 & & $\mathrm{R} \$ \mathbf{2 2 9 . 5 5 7 , 9 0}$ \\
\hline MATERIAL & VOLUME 3 MESES (kg) & $\begin{array}{l}\text { VOLUME } \\
3 \text { MESES } \\
\text { (t) }\end{array}$ & $\begin{array}{l}\text { VALOR ATERRO SANITÁRIO } \\
\text { (t) }\end{array}$ & $\begin{array}{l}\text { DESPESAS TRIMESTRAL } \\
\text { (R\$) }\end{array}$ \\
\hline Resíduo Orgânico & 14.120 & 14,12 & 61,32 & 865,84 \\
\hline Resíduo Comum & 67.280 & 67,28 & 61,32 & $4.125,61$ \\
\hline Lodo Ete & 98.090 & 98,09 & 61,32 & $6.014,88$ \\
\hline Carvão Ativado & 6.700 & 6,70 & 61,32 & 410,84 \\
\hline TOTAL & & 186,19 & & $\mathrm{R} \$ \quad 11.417,17$ \\
\hline
\end{tabular}

Fonte: Sistema TCI Soluções Ambientais (2019).

No Quadro 2, dividiu-se em 2 partes, sendo a primeira parte a dos materiais que podem ser reciclados e destinados para empresas que fazem o reaproveitamento do material. A segunda parte, é de resíduos que não é possível a sua reciclagem, que são restos de varrição, resíduos de banheiro e refeitórios, lodo da ETE Estação de Tratamento de Efluentes, onde é destinado o xarope descartado na produção das bebidas, e carvão ativado descartado da produção das bebidas.

Pode-se verificar que, ao invés de pagar pela destinação de todo o material antes da implantação da gestão de resíduos no Quadro 1, a empresa gera receita apresentada no quadro 2, destinando para aterro somente aquilo que não se pode destinar, com os dados levantados, podemos analisar a lucratividade que a empresa possui realizando a atividade de coleta seletiva e gestão de resíduos. Para fazer o levantamento e obter os resultados com o lucro gerado, foram levantadas todas as despesas que a empresa tem para implantação da gestão de resíduos dentro da fábrica. Por intermédio da base dados dos resíduos destinados nos quadros 1 e 2, pode-se analisar graficamente o resíduo que tem maior geração e maior volume, em termos de valor de mercado, nem sempre o maior volume é o que tem maior valor de mercado, para entender melhor a situação exposta, realizou-se a análise de dois produtos, apresentados na Figura 3.

Entre os materiais apresentado, destaca-se o vidro, que teve o maior volume coletado no período em análise. Vale ressaltar que o vidro é $100 \%$ reciclável, não ocorre perda de material no seu processo de fusão, ou seja, cerca de 172 toneladas deixam de ir para locais incorretos, gerando lucro para a empresa geradora do resíduo apesar de ser um produto com baixo valor de mercado, conforme dados apresentados:

Produto com maior volume no período de 3 meses: Vidro $172.370,00 \mathrm{~kg}$; Valor de mercado: $\mathbf{R} \$ \mathbf{0 , 0 7}$ centavos; Produto com menor volume e maior receita: Ref Pet 77.810,00 kg; Valor de mercado: $\mathbf{R} \$ 0,60$ centavos.

Na figura 4, é apresentado um gráfico para melhor entendimento visual dos dados levantados, os produtos é o vidro e o Ref Pet (Pet Retornável), este último, é da classe do Plástico, que também é 100\% reciclável, com isso, mais de 77 toneladas que deixam de ser lançados em local incorreto, gerando receita para a empresa geradora, ao invés de despesa. 


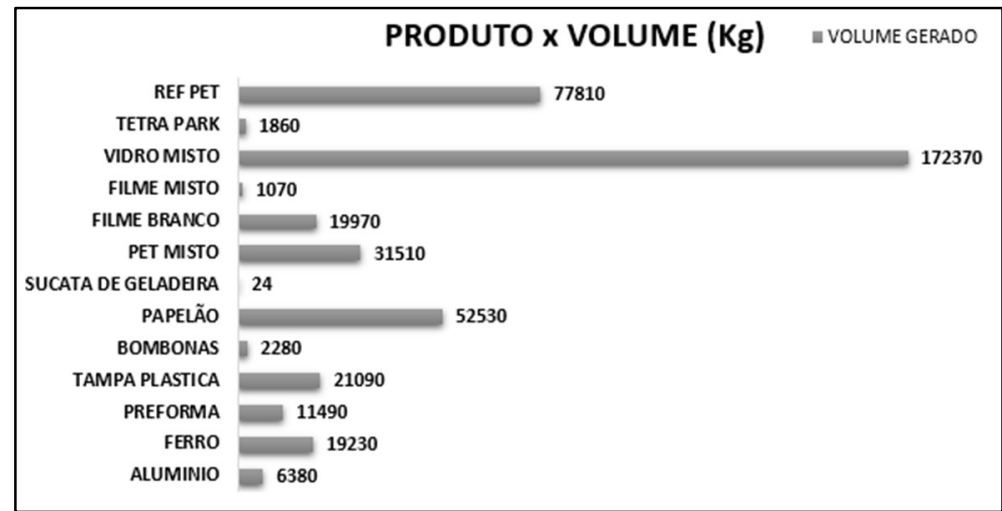

Figura 3: Produto $x$ Volume.

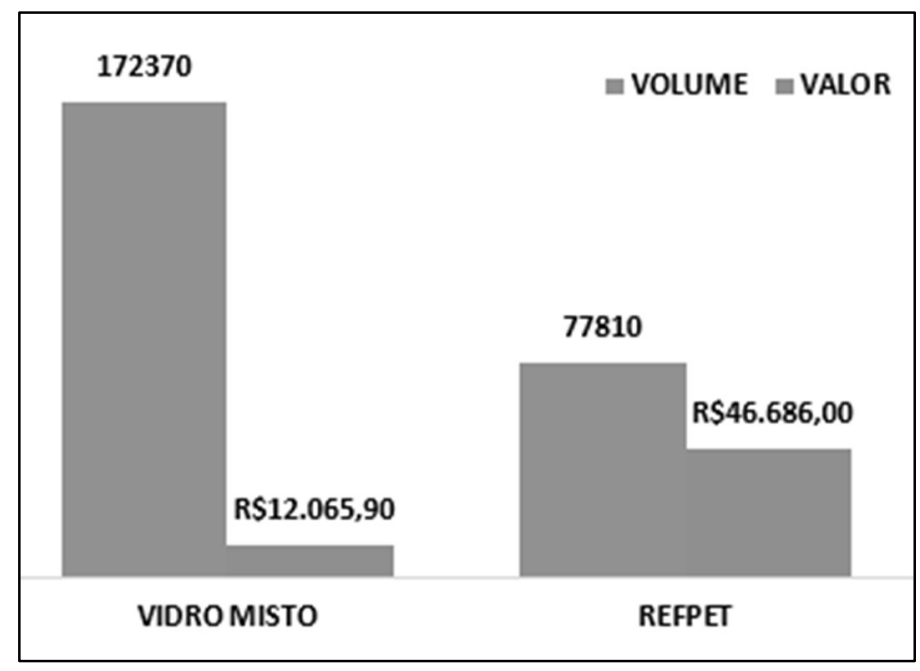

Figura 4: Volume $x$ Valor.

Com a elaboração de um cálculo simples se pode verificar que o material vidro, no período de 3 meses, conforme a Figura 4, apresenta 172,37 toneladas com o preço oferecido pelo mercado de $\mathrm{R} \$ 0,07$; tem-se a receita de $\mathrm{R} \$ 12.065,90$; quando se realiza a análise de outro produto com menor volume, mas com maior valor pago pelo mercado, o Ref Pet que tem volume de 77,81 e valor pago pelo mercado de $\mathrm{R} \$ 0,60$ o quilo, em relação ao vidro, tem uma receita de $\mathrm{R} \$ 46.686,00$. Em termos de receita para a empresa o valor é inversamente proporcional ao volume.

É importante analisar a situação porque os valores refletem diretamente na receita e estratégia da empresa, fazendo com que a mesma realize um planejamento voltando seus esforços para os materiais que obtém maior retorno, tornando ainda o processo dos materiais com maior volume e menor valor de mercado, mais ágil e com menores esforços para não ter retrabalhos e uso de mão de obra. Para não possuir uma maior despesa com a gestão de resíduos desse perfil, a empresa usa como estratégia direcionar os materiais retirando da fábrica e levando diretamente para o destinador final.

Como benefício da gestão integrada de resíduos, a empresa tem economia com a disposição final do aterro. Esse é o custo evitado e o foco deste trabalho, retirado do custo total que envolve o programa de coleta seletiva e reciclagem, o lixo que não é coletado, nem transportado e nem operado no aterro, e, portanto, sem os custos de compactação e aterramento. A implantação da Gestão Integrada de Resíduos na empresa de refrigerantes despendia de $\mathrm{R} \$ 61,32 /$ ton para o aterro sanitário com a destinação do resíduo, assim o volume que é retirado do reciclado que não vai para o aterro gera uma diminuição de gastos. 
Podemos destacar ainda que o custo que a empresa poderia despender SEM Gestão Integrada de Resíduos seria de R\$148.257,00 Custo anual com Aterro Sanitário. Já, com a implantação da Gestão Integrada de Resíduos o custo diminui para $\mathrm{R} \$$ 45.668,68 Custo anual com Aterro Sanitário. Economia de $\mathrm{R} \$ 102.588,32$ ou seja 69\%, valores baseados no levantamento dos Quadros 1 e 2.

Tais resultados fizeram considerar que, a continuar essa tendência na tipologia de materiais descartados, a empresa de gestão integrada de resíduos deverá direcionar seus esfoços para agilizar na operação interna em destinar uma quantidade maior de resíduos reciclados, otimizando espaço no transporte com materiais prensados e acondicionados de forma que possa transportar um maior volume para os recebedores de resíduos.

Os custos despendidos com a gestão integrada de resíduos, foram basicamente de cinco tipos: Mão de obra, equipamentos, gastos com combustíveis, despesas com o pagamento e destino para aterro e ainda o pagamento do material reciclado ao Gerador do resíduo, que conforme apresentado anteriormente, ganha destinando através da gestão integrada. Os insumos/despesas operacionais mensais levantadas neste estudo é de: $R \$ 71.967,72$

Custos é todo gasto relativo ao bem ou serviço utilizado na produção de outros bens ou serviços. Despesas ou Custos fixos são aqueles que não sofrem alteração de valor em caso de aumento ou diminuição da produção. Independem, portanto, do nível de atividade, conhecidos também como custo de estrutura. No Quadro 3, estão relacionados os insumos e despesas operacionais mensais com o serviço de Gestão Integrado de Resíduos dentro da Indústria de refrigerantes. Os valores foram repassados pela empresa de gestão ambiental, através de LBC - Levantamento Básico de Custos, método utilizado na empresa para auxiliar na tomada de decisão em relação a preço de venda de serviços e produtos.

Vale ressaltar que as despesas é tudo aquilo que a empresa terceirizada paga para fazer a gestão do resíduo, como o uso de insumos e ainda o valor pago pelo reciclado coletado do gerador, como informado neste trabalho, o gerador também recebe pela venda de seu resíduo a terceirizada. A receita é tudo aquilo que a terceirizada recebe do gerador para realizar o serviço, que está divido em três modos, um valor fixo que já é acertado em contrato e os valores variáveis através da venda do reciclado e da destinação do não reciclado.

Quadro 3: Despesa / Receita / Lucro.

\begin{tabular}{|c|c|c|c|c|}
\hline INSUMOS / DESPESAS OPERACIONAIS MENSAIS & VALOR & RECEITA & $\begin{array}{ll}\text { VALOR } & \text { (MÉDIA } \\
\text { MENSAL) } & \\
\end{array}$ & $\begin{array}{l}\text { LUCRO } \\
\text { LIQUIDO }\end{array}$ \\
\hline Mão de Obra & $\mathrm{R} \$ 20.000,00$ & \multirow{3}{*}{$\begin{array}{l}\text { Venda de Material } \\
\text { Reciclado }\end{array}$} & \multirow{3}{*}{$R \$ 76.519,13$} & \multirow{8}{*}{$\mathrm{R} \$ \mathbf{4 8 . 9 9 9 , 2 8}$} \\
\hline Equipamentos (prensa, triturador, paleteira, etc) & $\mathrm{R} \$ \quad 7.000,00$ & & & \\
\hline Insumos: Big Bags, limpeza & $2.000,00$ & & & \\
\hline Despesas com destinação para aterro (média mensal) & $\mathrm{R} \$ \quad 3.805,72$ & $\begin{array}{lr}\text { Valor pago } & \text { pelo } \\
\text { destino do } & \text { Não } \\
\text { Reciclado } & \text { a } \\
\text { terceirizada } & \end{array}$ & $\mathrm{R} \$ 10.984,16$ & \\
\hline Empilhadeira & $\mathrm{R} \$ 11.000,00$ & \multirow{3}{*}{$\begin{array}{l}\text { Custo fixo pago } \\
\text { pelo gerador a } \\
\text { terceirizada }\end{array}$} & \multirow{3}{*}{$\mathrm{R} \$ 33.463,71$} & \\
\hline Veículos (Combustível e Manutenção) & $\mathrm{R} \$ \mathbf{1 0 . 0 0 0 , 0 0}$ & & & \\
\hline Compra de Reciclado do Gerador Média Mensal & $\mathrm{R} \$ 18.162,00$ & & & \\
\hline TOTAL & $\mathrm{R} \$ 71.967,72$ & & $\mathrm{R} \$ 120.967,70$ & \\
\hline
\end{tabular}


Concluindo a análise dos resultados, podemos destacar com os valores apresentados através da média mensal no Quadro 3 que, apesar das despesas que a empresa gera, todo o trabalho é beneficiado pelo gerador, ao final do ciclo da gestão integrada de resíduos, a empresa ganha com a venda do reciclado para destinadores finais, e ainda realiza o serviço dentro da fábrica destinando adequadamente o resíduos não reciclados.

Segundo Ferreira (2018), a lucratividade é o resultado de diversos fatores envolvidos, que apesar do custo que a empresa investe em contratar empresa especializada, mão de obra e divesos insumos, a geração de resíduos que antes era despesa, passa a ser lucro, e um investimento visto com bons olhos por grandes empresas, o Quadro 3, apresenta dados mensais em que mais de 48 mil reais entra no caixa da empresa, através de um gerenciamento de resíduos.

\section{CONCLUSÕES}

A pesquisa mostrou que para se obter benefício em dinheiro, ou seja, lucro, em um programa de Gestão Integrado de Resíduos dentro de uma indústria, é preciso um planejamento detalhado de todas as ações a serem realizadas. É importante lembrar que para o cálculo da relação custo/benefício, nos valores obtidos não estão incluídos os benefícios ambientais, sociais e de educação ambiental conseguidos com a implantação da gestão integrada de resíduos.

Depois de ter estudado a importância da coleta seletiva, o gerenciamento dos materiais e saber um pouco mais sobre a conscientização e a educação ambiental, podemos concluir que ainda há muito o que ser estudado e compreendido sobre o assunto, que é muito importante nos dias atuais, pois abrange questões ambientais, sociais e econômicas.

O lixo é símbolo da época de consumo atual e tema privilegiado para a Educação Ambiental. Seguindo sua trajetória, desde a matéria prima (recurso natural inicial) até o bem de consumo e seu descarte, vários são os passos pelos quais passa a matéria, em sua transformação pela ação humana. A coleta seletiva de materiais recicláveis é um caminho para educar e mudar comportamentos. Aliás, caminho muito oportuno, considerando a situação crítica de limpeza urbana e disposição final de lixo.

Neste artigo, que teve como principal objetivo apresentar a vantagem da implantação da gestão integrada de resíduos dentro de uma empresa, apresentando a receita e as estratégias utilizadas para obter resultados favoráveis, obteve-se resultados positivos. Dentre os dados utilizados para os resultados deste trabalho, pode-se destacar que a reciclagem ainda é a melhor opção para obter lucros com resíduos e destina-los de forma correta. É evidente que a situação do lixo, dentro do quadro de degradação ambiental, é grave, necessitando de estratégias inovadoras para evitar custos. Porém o que foi apresentado neste trabalho, mostra que o prejuízo se transforma em receita, confirmando o que a frase de Lavoisier diz "Na Natureza nada se cria, nada se perde, tudo se transforma".

As principais dificuldades no processo da implantação da gestão de resíduos dentro de uma fábrica de refrigerante que podem aparecer segundo a empresa terceirizada é, falta de alinhamento entre a Logística e Operação, isso porque qualquer falta ou erro de comunicação pode levar retrabalho e aumento de recursos 
operacionais, por isso é levantado neste trabalho a questão do planejamento entre as áreas envolvidas, atraso na coleta dos resíduos, que gera superlotação de material na central de resíduos em um curto período de tempo e ainda mão de obra desqualificada. O sucesso para essa implantação se dá no treinamento de funcionários especializados na área e comunicação em todas as etapas do serviço. Reciclar é economizar energia, poupar recursos naturais e trazer de volta ao ciclo produtivo o resíduo que seria jogado fora, para que o mesmo seja usado novamente como matéria prima, gerando Lucro para a empresa geradora do resíduo e para uma cadeia de empresas que se beneficiam com essa logística reversa.

\section{REFERÊNCIAS}

CARVALHO, A. M. R.. Cooperativa de Catadores de Materiais Recicláveis de Assis - COOCASSIS: Espaço de trabalho e de sociabilidade e seus desdobramentos na consciência. Tese (Doutorado em Psicologia Social) Instituto de Psicologia da Universidade de São Paulo, São Paulo, 2008.

CARVALHO, J. M. G.. Vida e lixo: a situação de fragilidade dos catadores de material reciclável e os limites de reciclagem. 2005.

CORTEZ, A. T. C.. A gestão de resíduos sólidos domiciliares: Coleta seletiva e reciclagem: A Experiência em Rio Claro (SP). Tese de Livre Docência apresentada ao Instituto de Geociências e Ciências Exatas, Universidade Estadual Paulista, Rio Claro, 2002.

FERREIRA, A. L.. Gestão Integrada de Resíduos. Portal resíduos sólidos. 2018.

HEIDEN, A. I. V. D.. Cooperativas de reciclagem de lixo e inclusão social: o caso do município de Itaúna MG.
Dissertação (Tese) - Universidade do Estado de Minas Gerais, Belo Horizonte, 2007.

IBGE. Instituto Brasileiro de Geografia e Estatística. Relatório de indicadores de Desenvolvimento Sustentável. Rio de Janeiro: IBGE, 2010.

LACERDA, L.. Armazenagem estratégica: analisando novos conceitos. Medianeira, 2006.

MONTEIRO, J. H. P.; ZVEIBIL, V. Z.. Manual de gerenciamento integrado de resíduos sólidos. Rio de Janeiro: Instituto Brasileiro de Administração Municipal, 2001.

PNRS: Política Nacional de Resíduos Sólidos. Lei Federal n.12.305 de 2 de agosto de 2010. 2010.

VILHENA, A.. Guia da coleta seletiva de lixo. São Paulo: CEMPRE, 1999.

YIN, R. K.. Estudo de caso: planejamento e métodos. 2 ed. Porto Alegre: Bookman, 2001.

A CBPC - Companhia Brasileira de Produção Científica (CNPJ: 11.221.422/0001-03) detém os direitos materiais desta publicação. Os direitos referem-se à publicação do trabalho em qualquer parte do mundo, incluindo os direitos às renovações, expansões e disseminações da contribuição, bem como outros direitos subsidiários. Todos os trabalhos publicados eletronicamente poderão posteriormente ser publicados em coletâneas impressas sob coordenação da Sustenere Publishing, da Companhia Brasileira de Produção Científica e seus parceiros autorizados. Os (as) autores (as) preservam os direitos autorais, mas não têm permissão para a publicação da contribuição em outro meio, impresso ou digital, em português ou em tradução. 